\title{
Analysis on regional vulnerability to rising energy prices: Focus on Sardinia (Italy)
}

\author{
Gavino Mariotti \\ Department of Humanistic and Social Sciences, University of Sassari, Italy
}

Email address:

mariotti@uniss.it

\section{To cite this article:}

Gavino Mariotti. Analysis on Regional Vulnerability to Rising Energy Prices: Focus on Sardinia (Italy). Social Sciences. Special Issue: Geographical evidence in changing Europe. Vol. 3, No. 4-1, 2014, pp. 57-60. doi: 10.11648/j.ss.s.2014030401.16

\begin{abstract}
The paper analyzes the impact of the increasing energy costs on regional economic performances. In particular, the study focuses on the impact of energy costs on the transport system, with particular reference to the maritime transport, attributing it directly to the relevant importance of the local tourism industry. It shows the high dependence of the local economic system on the regional transport system both internally and externally, and consequently the loss of regional competitiveness as a result of rising oil prices. Moreover the work reviews the principal local policy measures about energy strategies and it highlights the low use of renewable energy sources in spite of the high regional PV potential recognised in several environmental researches.
\end{abstract}

Keywords: Regional Vulnerability, Competitiveness, Energy Strategies

\section{Introduction}

The ReRisk Applied Reserch ESPON project published in 2013 [9] examines the vulnerability of territories in Europe in reference to the increase in energy prices. The research, which relates the factors "environment" "economic growth" - " energy demand", examines the European territory in relation to the degree of dependence on fossil fuels and check the potential of each territory about the implementation of sustainable energy production. On the basis of evidence produced by the ESPON research, the following study, goes to analyze the degree of dependence of the local economic system of the region of Sardinia (Italy) and the local energy demand. It identifies the economic sectors most developed at territorial reality considered, highlighting the degree of vulnerability to the same with respect to the increase in oil prices. The high incidence of the fuel costs used in the transport system acquire a significance in this study, specifically, due to the condition of insularity that characterizes the region considered. For this reason the analysis focuses on a specific item of cost, such as maritime transport, which weigh heavily on the final cost of the goods and on the people movement.

\section{Local Economy and Fossil Fuel Dependence. The Case of Sardinia}

\subsection{Regional Framework}

Sardinia is an island situated in a strategic position in the middle of the Mediterranean Sea. It is the second largest island in the Mediterranean with an area of $24,090 \mathrm{~km}^{2}$, that includes offshore islands.

The island has a peculiar landscape, characterized by natural and historical heritage, and fragile ecosystems that are in part legally protected. These sites are widespread across all the region and are classified as national and regional parks, preserved marine areas and natural monuments. This natural resource has been preserved over time mainly thanks to a low density population in Sardinia it is estimated at 69 people per $\mathrm{km}^{2}$, almost a third less than the national average [19].

Nowadays, after about 50 years of investment, tourism activities have become essential for the Sardinian economy, not only for the contribution to the GDP, but also to employment.

The tourism industry has certainly influenced the economic growth of the territory, but it is important to note that the whole service sector has been of particular importance for the local economy. In fact, the percentage composition for the added value of the different activities is 
$77.4 \%$ in the tertiary sector, $19.2 \%$ in the industrial sector and $3.4 \%$ in the primary sector (which also includes fishing, agriculture, sheep-rearing and also the mining activities connected to the mineral rich soil of copper, coal, granite and bauxite [4].

With regard to the secondary sector although it is not particularly developed, it is appropriate to recognise the peculiar production model that characterizes it .

Specifically the manufacturing and production of handicrafts that have grown over the years into important ]agglomeration economies. These have grown by concentrating, different small and medium sized firms (SMEs) working in a homogeneous sectors, in the same place. At the regional level, the decree passed by the local government in 1997 approved the creation of the four industrial districts: cork, marble, traditional Sardinian rugs and granite. There is also the traditional model of industrial production covering the chemical and petrolchemical areas.

With reference to the labour market the result is that over $75 \%$ of the Sardinian workforce is employed in the service sector, while only $19 \%$ work in the industry sector and $5 \%$ in the primary one (Fig.1).

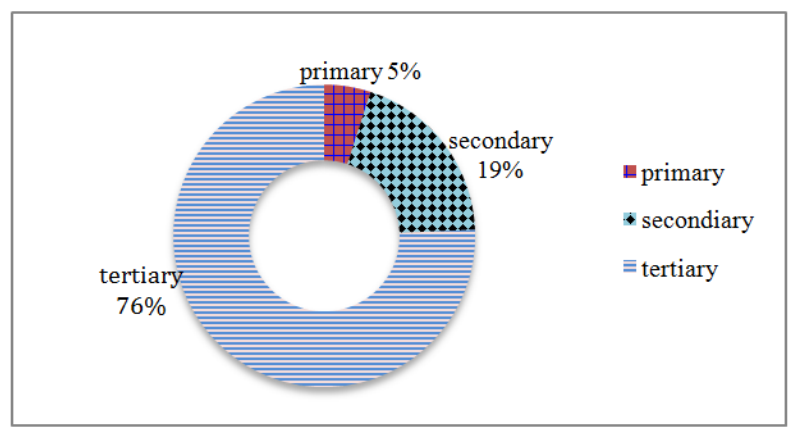

Fig 1. Labour market in Sardinia, year 2010.( Istat, Labour Force Survery, 2011)

It is also important to note that the Sardinian employment rate for the population aged between 20 and 64 , amounts to $54,6 \%$, while the national rate is $61.1 \%$.

This significant difference is also found in macroeconomic aggregates. The regional GDP per capita is in fact $20 \%$ lower than national average (Fig. 2).

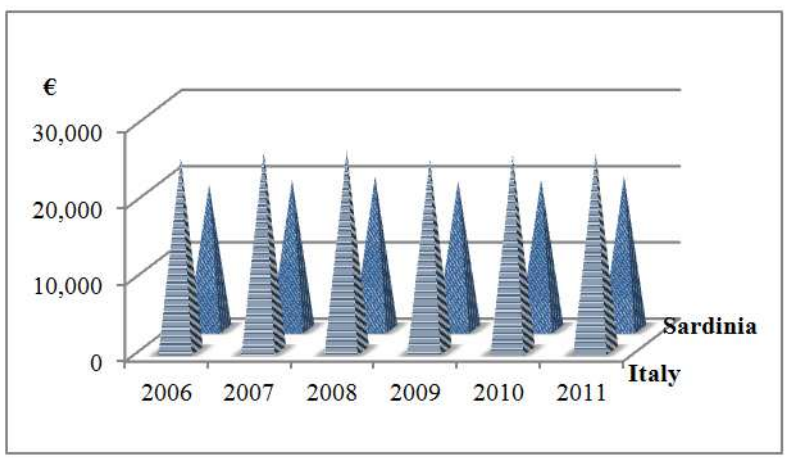

Fig 2. GDP per capita by region, current prices. Years
2006-2011.( Eurostat, Istat, 2014)

This difference is mainly attributable to the insulare condition of Sardinia which creates higher costs in all economic sectors, caused by the more onerous transport costs.

Obviously, the transport is not a direct factor in the GDP calculation but it plays a very important indirect role. Tourism is the economic sector which should act as a leverage for GDP increase, but it is significantly affected by the considerable costs of transport. Infact, in Sardinia these are $100 \%$ higher than in the rest of Italy, and showed an increasing trend, parallel to the increase of petroleum's price. At the same time, it is estimated that the price of petroleum will continue to increase to reach new records until it meets the threshold of his own availability. (Fig.3)

\subsection{Transport Costs: The Dramatic Increase}

When we talk about transport in relation to Sardinia we refer to the movement to and from the island because the internal transport network is practically absent: there neither electrified railways nor highways nor shipping waterways.

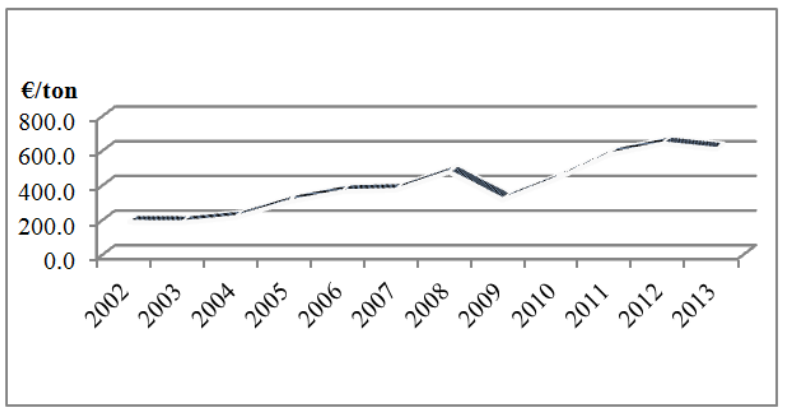

Fig 3. Cost of petroleum imported in Italy.( UPI, 2013)

The incidence of energy costs compared to the total costs of transport are shown in the follow table (Table 1)

Table 1. Percentage of energy costs for the different modalities of transport.

\begin{tabular}{cc}
\hline Modality of transport & $\begin{array}{r}\text { Percentage of energy cost compared to } \\
\text { the total cost of transport }\end{array}$ \\
\hline road transport & $25 \%$ \\
rail transport -diesel & $27 \%$ \\
rail transport - electric & $12 \%$ \\
internal navigation & $21 \%$ \\
sea shipping & $50 \%$ \\
air transport & $33 \%$ \\
\hline
\end{tabular}

Source: CCNR and DG TREN, 2007

The percentage of energy costs in sea and air transport are respectively $50 \%$ and $33 \%$. Sea shipping and air transport are the modalities most likely to increase their price with the rising oil price.

This has been verified in the trend of the tickets prices issued by private operators involved in the maritime transport services to and from Sardinia, departing from or 
arriving from the Italian peninsula.

A substantial sea travel ticket price increase was expected, considering that the cost of imported oil in Italy increased in 2011 about $32 \%$ more this is confirmed in the following table (Table 2).

Such a dramatic increase of oil prices has a negative impact both in terms of business competitiveness and in social terms. Social consequences are because the household incomes suffer from the inflation arising from the effect of the rising oil prices. At the same time a physiological process of the regression of oil demand.

In addition to all of this it is important to highlight the incoming and pressing crisis of the petrochemical industry that is struggling to reach the break even point with the increase in price of the raw materials.

Yet again the economic crisis has created social problems: in 2010 and 2011 the Sardinian petrochemical industry responded to the crisis with massive layoffs of employees.

Futhermore in 2012 the Italian Authority for Energy has increased energy prices three times. Salaries and pensions have not been adjusted in response to these increases. As a result, on the one hand companies have reduced their competitiveness, and on the other consumption has been reduced.

It should also be noted that the demand for electricity rises in Sardinia, like the other southern European countries, during the summer months, due to a significant increase in maximum climatic temperature. The demand for cooling will tend to increase in the coming years as a result of climate change

Table 2. Price comparison average 2010 - 2011.

\begin{tabular}{cccc}
\hline company & average prices 2010 & average prices variation \% \\
2011 & 2011- 2010 \\
\hline $\begin{array}{c}\text { Forship "Sardinia } \\
\text { Ferries" }\end{array}$ & $80-100 €$ & $140-160 €$ & $130-150 \%$ \\
Moby & $110-130 €$ & $200-220 €$ & $90-110 \%$ \\
GNV & $180-200 €$ & $250-270 €$ & $50-60 \%$ \\
SNAV & $90-110 €$ & $190-210 €$ & $80-100 \%$ \\
Everage & $120-140 €$ & $190-210 €$ & $90-110 \%$ \\
\hline
\end{tabular}

Source: Antitrust Authority, 2011

Diversification in energy sources would reduce dependence on crude oil. Sardinia may increase the production of renewable energy by exploiting the high PV potential $(1.390 / \mathrm{kwp})$ and the strong wind potential $(93.830 / \mathrm{m} / \mathrm{s})$ [9]. Currently the share of energy production from renewable sources amounts to $18 \%$. Of this $42 \%$ is attributed to wind power, bioenergy $26 \%, 18 \%$ hydroelectric and 14\% solar (GSE, 2011). The Sardinian energy production, both renewable and non-renewable, is run by large companies that place part of their production unit in Sardinia but the general management is outside the region. These companies have invested heavily in the island territory, which for geo-morphological reasons lend itself to energy production. Therefore, much of the local energy production is destined to the outside markets.

\section{Conclusions}

In recent years, some things are changing in Sardinia, in terms of energy supplies. The Autonomous Region of Sardinia, led by the EU targets for 2020, is implementing an energy policy perfectly in line with the requirements of national legislation and EU directives. In 2006 PERS (Regional Environmental Strategic Plan) was introduced to identify the level of energy consumption and renewable energy sources compatible with the territory. Decrees and regional laws were then promulgated to regulate the criteria for the construction of energy systems. Regional and national governments introduced three types of tools to faciliate an increase the renewable energy: 1) Contributions for the production: this rewards the production of electricity produced and put into the network, 2) Contributions for plants: funding for the construction of the renewable energy system, 3) Tax deductions: proportionate to the investments made.

Finally, considering the territorial peculiarities of the region analysed, the energy potentials, the economic structure and in the light of set of problems identified, it is possible to suppose the best development path in the medium and long term is in the energy sector.

In this case it is essential to support and promote the implementation of photovoltaic and wind renewable energy power plants, harnessing the potential of the territory. Investments in this area should involve both the public and the private sector because only the widespread dissemination of renewable energy production facilities can in the long run achieve complete independence from fossil fuels.

\section{References}

[1] S.C. Bhattacharryya, Energy Economics, Springer - Verlag, 2011, London.

[2] S. G. Cecchetti, R. Moessner , Commodity prices and inflation dynamics BIS Quarterly Review, December 2008, Available from Internet: http://www.bis.org/publ/qtrpdf/r_qt0812f.pdf.

[3] CRENoS, Economia della Sardegna. $18^{\circ}$ rapporto 2011, Cuec, 2011, Cagliari.

[4] CRENoS, Economia della Sardegna. $19^{\circ}$ rapporto 2012, Cuec, 2012, Cagliari.

[5] CRENoS, Economia della Sardegna. 20 rapporto 2012, Cuec, 2013, Cagliari

[6] ESPON Territorial dynamics in Europe, Trends in population development, Territorial Observation n.1, 2008, Available from Internet: http://www.espon.eu/export/sites/default/Documents/Publica tions/TerritorialObservations/TrendsInternetRoll-out/TO4_f or_web.pdf 
[7] ESPON, Territorial dynamics in Europe, Trends in economic performance of European Regions 2000-2006, Territorial Observation n.3, 2010, Available from Internet: http://www.espon.eu/export/sites/default/Documents/Publica tions/TerritorialObservations/TrendsInEconomicPerformanc e/ESPON-TO3_web.pdf

[8] ESPON, New evidence on smart, sustainable and inclusive territories, First ESPON 2013 Synthesis Report, Available from Internet: http://www.espon.eu/export/sites/default/Documents/Publica tions/SynthesisReport/FirstOctober10/fullversion.pdf

[9] ESPON, Regions at Risk of Energy Poverty (ReRisk), Applied Research, Final Report, 2013 Available from Internet:

http://www.espon.eu/export/sites/default/Documents/Project s/AppliedResearch/ReRISK/ReRiskfinalreport.pdf.

[10] GSE, Rapporto statistico 2011. Impianti a fonti rinnovabili.

[11] OECD, Decoupling the environmental impacts of transport from economic growth, OECD Publishing, 2006, Paris.

[12] Parlamento Europeo, L'impatto delle oscillazioni del prezzo del petrolio sui trasporti, Direzione Generale delle Politiche Interne dell'Unione Euopea. Unità tematica B - Politiche strutturali e di coesione, POLDEP, 2009, Bruxelles.

[13] E. Quinet, R. Vickerman, Principles of transport economics, Edgar Elgar Publising, 2004, Nothampton.

[14] http://www.autorita.energia.it/it/index.htm

[15] http://database.espon.eu/

[16] http://www.espon.eu/main/

[17] http://epp.eurostat.ec.europa.eu

[18] http://www.ilsole24ore.com

[19] http://www.istat.it/it/

[20] http://www.mit.gov.it/mit/site.php

[21] http://www.regione.sardegna.it

[22] http://www.terna.it

[23] http://www.unionepetrolifera.it/it 